\title{
Incidência de Cryptosporidium em bezerros jovens criados em sistema extensivo: resultados preliminares de um estudo longitudinal
}

Felippe Danyel Cardoso Martins", José Antonio Bessegatto, Winni Alves Ladeia, Manuela Ferraz Valadares, Roberta Lemos Freire, Juliana Massitel Curti, Caroline Ambiel Barros Gil Duarte, Fabricio Moreira Cerri, Carlos Henrique Montemor, Júlio Augusto Naylor Lisbôa

Universidade Estadual de Londrina (UEL), Londrina, PR, Brasil

*Autor correspondente

e-mail: fmartins@uel.br

\section{Resumo}

A cryptosporidiose é uma doença causada por protozoários do gênero Cryptosporidium, conhecidos por infectarem uma grande gama de hospedeiros. Em bezerros, o Cryptosporidium spp. é um importante agente causador de diarreias, gerando perdas econômicas. Além disso, bovinos podem hospedar espécies zoonóticas de importância em saúde pública. A infecção ocorre a partir da ingestão de oocistos, eliminados nas fezes de animais infectados, presentes no ambiente, o que facilita a disseminação da doença em sistemas de criação intensivos. Por outro lado, o manejo extensivo pode reduzir o número de animais infectados. O objetivo foi realizar um estudo longitudinal para avaliar a incidência de Cryptosporidium spp. em dois grupos de bezerros criados em sistema extensivo. Doze bezerros da raça Nelore (NEL) e onze bezerros cruzados Nelore vs Britânico (CRU) tiveram até o momento fezes coletadas nas idades de 15, 28, 60 e 90 dias, classificadas como diarreicas ou não de acordo com a consistência. A técnica de Ziehl-Neelsen modificada foi utilizada para o diagnóstico. Durante o período estudado, todos os bezerros em ao menos um momento foram considerados positivos para Cryptosporidium (100\% de prevalência no período). Em $52,38 \%$ dos animais foi constatada a presença de diarreia; a incidência variou de 4,76\% a 34,78\%, tendo sido a maior constatada com 15 dias de vida. Considerando Cryptosporidium, a incidência variou de 39,13\% a 71,43\%, a maior sendo encontrada com 28 dias; dentro dos grupos, a incidência variou de $40 \%$ a $60 \%$ no grupo NEL e 27,27\% a 81,81\% no CRU. Embora o Cryptosporidium spp. possa não ser a única etiologia de diarreia nesse período, nossos resultados demonstram que a criptosporidiose está disseminada no rebanho. As frequências se assemelham àquelas encontradas em bovinos leiteiros confinados, fato que contesta a hipótese de que em criações a pasto há menor prevalência em relação aos sistemas confinados. A menor incidência encontrada (39,13\%) ainda representa uma grande frequência deste protozoário nesta população. A manutenção da infecção no período pós-neonatal demonstra que animais mais velhos podem 
atuar como fonte de infecção aos mais novos e vice-versa. A epidemiologia da criptosporidiose em bovinos é complexa; quatro espécies são comuns em bovinos e cada uma prevalece em determinada idade. 0 real conhecimento quanto à dinâmica da infecção só poderá ser alcançada por meio de técnicas de biologia molecular capazes de discriminar as espécies, o que poderá trazer novas perspectivas para o controle desta infecção. Cryptosporidium spp. esteve presente nas fezes de todos os animais estudados em pelo menos um momento. A maior incidência foi encontrada aos 28 dias de vida. 0 grupo CRU teve maior variação da incidência entre as coletas em relação ao grupo NEL. Estudos moleculares são necessários para elucidar a dinâmica de transmissão deste protozoário. 